\title{
The caudal bursa in the Heligmonellidae (Nematoda: Trichostrongylina). ChARACTERIZATION AND HYPOTHESIS ON ITS EVOLUTION
}

\author{
DURETTE-DESSET M.C.* \& DIGIANI M.C.**
}

\section{Summary:}

The different patterns of the caudal bursa of the Heligmonellidae (Nematoda) are redefined, taking into account the grouping of rays 2-6 and the sequence of origin of these rays from their common trunk. The type of symmetry of the caudal bursa is also redefined. The following patterns were observed and characterized: the basic patterns: types 2-3, 2-2-1, 1-3-1 and 1-4 and the intermediary patterns: type 2-3 tending to type 2-2-1, type 2-2-1 tending to type 1-3-1, type 1-3-1 tending to type 1-4 and type 2-2-1 tending to type 1-4. An evolutionary interpretation of the patterns is attempted and seems to follow the direction: $2-3$ to $2-2-1$ to $1-3-1$ to $1-4$. Seven atypical patterns are described. The caudal bursae were classified based on their symmetry: subsymmetrical, dissymmetrical and asymmetrical. Independently of the type of symmetry, the two latero-ventral lobes may have the same or different patterns. The type of symmetry, the ratio between the two latero-ventral lobes and a characteristic pattern were utilized to characterize the caudal bursae at the level of the genus and the subfamily. The combination of the right/left ratio and the type of symmetry gives heterogeneous results, with no real association between these characters. The most conspicuous asymmetries and dissymmetries were found among the Nippostrongylinae. The most frequent pattern in the Heligmonellidae is the basic type 2-2-1; types 1-3-1 and 1-4 are less frequent but are characteristic of several genera; type 1-4 is absent from the Heligmonellinae. Whatever the pattern, in the Heligmonellidae rays 4 and 5 are the last to diverge from the common trunk of rays 2-6.

KEY WORDS: Nematoda, Heligmonellidae, bursal pattern, bursal symmetry, evolution.

\section{INTRODUCTION}

T he Trichostrongylina have a common origin with the other suborders of the order Strongylida, arising from an ancestor close to the Rhabditida (Durette-Desset et al., 1994; Blaxter et al., 1998, 2001). In the strongylid nematodes, unlike the

\footnotetext{
* Département de Systématique et Evolution, Muséum national d'Histoire naturelle, UMR 7138 associée au CNRS, CP 52, 61, rue Buffon 75231 Paris Cedex 05, France.

** CONICET. División Zoología Invertebrados, Museo de La Plata, Paseo del Bosque s/n 1900 La Plata, Argentina.

Correspondence: Dr María Celina Digiani.

Tel.: 542214257744 , int. 132 .

Fax: 542214257527 .

E-mail: mdigiani@fcnym.unlp.edu.ar
}

Résumé : LE PATTERN DE LA BOURSE CAUDALE CHEZ LES Heligmonellidae (Nematoda: Trichostrongylina). Caractérisation ET HYPOTHĖSE SUR SON ÉVOLUTION

Les différents patterns de la bourse caudale chez les Heligmonellidae (Nematoda) sont redéfinis en tenant compte du groupement des côtes 2-6 et de la séquence d'apparition de ces côtes sur leur tronc commun. Le type de symétrie est également redéfini. Les patterns suivants sont observés et caractérisés : les patterns de base : type 2-3, 2-2-1, 1-3-1 et 1-4 et les patterns intermédiaires: type 2-3 à tendance 2-2-1, 2-2-1 à tendance 1-3-1, 1-3-1 à tendance 1-4 et 2-2-1 à tendance 1-4. Une interprétation évolutive des patterns est proposée et semble suivre la direction : 2-3 vers 2-2-1 vers 1-3-1 vers 1-4. Sept patterns atypiques sont décrits. Les bourses caudales sont classifiées selon leur symétrie en : subsymétrique, dissymétrique et asymétrique. Indépendamment du type de symétrie, les deux lobes latéro-ventraux peuvent avoir un pattern identique ou différent. Le type de symétrie, le rapport évolutif entre les deux lobes latéro-ventraux et un type de pattern caractéristique ont été utilisés pour caractériser les bourses caudales au niveau du genre et de la sous-famille. La combinaison du rapport droite/gauche et le type de symétrie donnent des résultats hétérogènes sans véritable lien entre ces caractères. Les asymétries et les dissymétries les plus manifestes sont trouvées parmi les Nippostrongylinae. Le pattern le plus fréquemment rencontré chez les Heligmonellidae est le type de base 2-2-1; les types 1-3-1 et 1-4 sont moins fréquents mais caractéristiques de plusieurs genres; le type 1-4 est absent chez les Heligmonellinae. Chez les Heligmonellidae, quel que soit le pattern, les côtes 4 et 5 sont les dernières à diverger du tronc commun aux côtes 2-6.

MOTS-CLÉS : Nematoda, Heligmonellidae, pattern boursal, symétrie boursale, évolution.

Rhabditida, the tail of the male widens in order to form a caudal bursa made up of two latero-ventral lobes and one dorsal lobe. Therefore the caudal bursa is a derived character regarded as a synpomorphy for the Strongylida. Durette-Desset \& Chabaud (1981) and Durette-Desset (1985), proposed a classification of the Trichostrongyloidea which they divided into three supra familiar groups: the "Trichostrongylids", the "Molineids" and the "Heligmosomids". In these classifications, they highlighted various types of caudal bursae, based mainly on the grouping of rays 2 to 6 (i.e. the rays supporting the latero-ventral lobes) (Fig. 1). In 1981, four patterns were defined: 1-3-1, characteristic of the "Trichostrongylids", 2-1-2, characteristic of the "Molineids" and 2-2-1 and 3-2, characteristic of the "Heligmosomids". Durette-Desset (1985) added type 


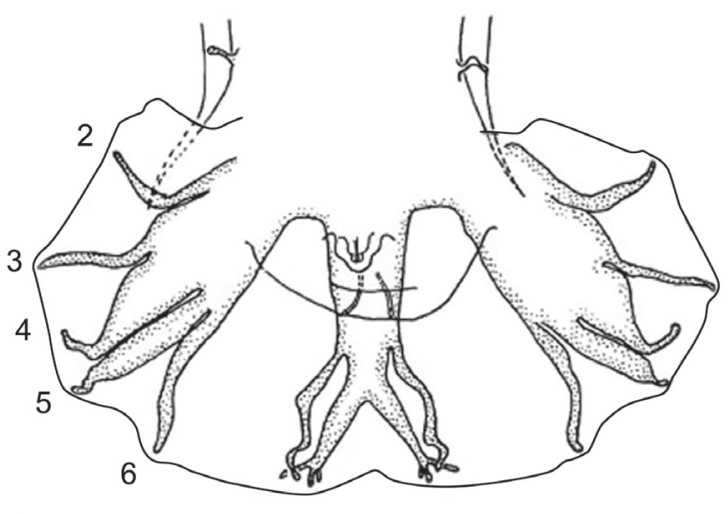

Fig. 1. - Numbering of rays 2 to 6 according to Chabaud et al. (1970).

Rays 2 and 3: ventral rays. Ray 2: ventro-ventral ray. Ray 3: lateroventral ray. Rays 4-6: lateral trident. Ray 4: externo-lateral ray. Ray 5: medio-lateral ray. Ray 6: postero-lateral ray. Ex: Pudica gonosoma Cassone \& Durette-Desset, 1991. After Cassone \& Durette-Desset (1999), modified. Scale-bar: $50 \mu \mathrm{m}$.

2-3 and specified that each grouping is characteristic of a given evolutionary line or a given family. Then, Durette-Desset \& Chabaud (1993) raised the Trichostrongyloidea to a suborder: the Trichostrongylina and each supra familiar group became a superfamily: the Trichostrongyloidea, the Molineoidea and the Heligmosomoidea.

This descriptive system however seems to us to be insufficient to properly describe the caudal bursae of some Nippostrongylinae, especially the genera such as Heligmonina Baylis, 1928 and Stilestrongylus Freitas, Lent \& Almeida, 1937, which do not show the same pattern in each lateral lobe. Within the framework of a revision of the Heligmonellidae, the aim of this work is to redefine the different patterns of the caudal bursa found within this family, taking into account not only the grouping of rays 2-6 but also the sequence of origin of these rays from their common trunk. The type of symmetry of the caudal bursa is also redefined. This enables us not only to make the descriptions of the caudal bursae more accurate, but also to highlight the characteristic type(s) of pattern within each genus and to attempt an evolutionary interpretation of the patterns.

\section{MATERIALS AND METHODS}

T The elements usually considered in the description of a caudal bursa (CB) are: symmetry, pattern of latero-ventral lobes, development of the dorsal lobe and characters of the dorsal ray and rays 8 . The characters of the dorsal ray and rays 8 are not treated in this work. Some terms concerning the symmetry and the pattern of the latero-ventral lobes are redefined as follows.

\section{TYPES OF SYMMETRY}

There are three types, which concern the degree of development of the latero-ventral lobes in relation to the sagittal axis of the worm:

- Subsymmetrical bursae (CB SS): both lobes are of similar size and shape in relation to the axis of the dorsal ray, which passes through the sagittal axis of the worm (Fig. 2a).

- Dissymmetrical bursae (CB DS): One lobe is larger than the other in relation to the axis of the dorsal ray, which passes through the sagittal axis of the worm. When the right lobe (RL) is larger it is cited as CB DS $\mathrm{RL}^{+}$. When the left lobe (LL) is larger it is cited as CB DS LL+ (Fig. 2b).

- Asymmetrical bursae (CB AS): The axis of the dorsal ray does not pass through the sagittal axis but is displaced to the right or the left side of the worm. One lobe may or may not be larger than the other in relation to this axis. When the right lobe (RL) is larger it is cited as CB AS RL+. When the left lobe (LL) is larger it is cited as CB AS LL+ (Fig. 2c).

\section{TYPES OF PATTERN}

The main features considered in the definition of the patterns are the grouping of the rays and the sequence of origin (or divergence) of these rays from their common trunk. The level of divergence of a ray from a common trunk (rays 2 to 6,3 to 5 or 3 to 6 ) is calculated on a straight line represented by ray 4; at the level of divergence another line is traced perpendicularly to the first one, as shown in Fig. 2 d.

- Basic patterns: rays 2 to 6 show a characteristic arrangement of the following types: type 2-3 (Fig. 3a); type 2-2-1 (Fig. 3b); type 1-3-1 (Fig. 3c); type 1-4 (Fig. 3d).

- Intermediary patterns (or transitional types from a basic type to another): rays 2 to 6 show an intermediary arrangement with features of two basic types: type 2-3 tending to type 2-2-1 (2-3 t 2-2-1) (Fig. 3e); type 2-2-1 tending to type 1-3-1 (2-2-1 t 1-3-1) (Fig. 3f); type 1-3-1 tending to type 1-4 (1-3-1 t 1-4) (Fig. 3g); type 2-2-1 tending to type $1-4(2-2-1$ t $1-4)$ (Fig. 3 h).

\section{LITERATURE DATA}

The data were compiled from descriptions published in the literature. We took into account only the caudal bursae where both latero-ventral lobes, or at least one, was spread out. In the latter case, the lobe was treated separately and the pattern was not extrapolated to the entire bursa. 
The systematic position of some species remains uncertain since, even if the caudal bursa is completely described, this is not the case with the synlophe. These species have therefore not been considered in this work. They are as follows: Durettestrongylus travassosi (Lent \& Freitas, 1938), Heligmonella vladimiri Sadovskaja, 1952, Heligmonina vogeli Khalil, 1931, Heligmonoides crassidorsualis Franco, 1967, Heligmonoides mirzai Smales, 2008, Heligmosomum delta Travassos, 1921, Longistriata degusi Babero \& Cattan, 1975, Longistriata castrosilvai Almeida, 1934, Longistriata fortuita Freitas, Lent \& Almeida, 1937, Longistriata perfida Travassos, 1943, Gobindonema boodugi Sood \& Parshad 1974, Morganiella cricetuli Yin \& Zhang, 1981. They are here considered as Heligmonellidae incertae sedis since their generic allocation is not possible. In the particular case of $H$. crassidorsualis and $H$. mirzai, both were considered as Nippostrongylinae incertae sedis by Durette-Desset \& Digiani (2010). Another species not treated is Nesomystrongylus fissicauda Durette-Desset, Lehtonen \& Haukisalmi, 2002. This species shares more characters with the Heligmosomidae than with the Heligmonellidae, i.e. presence of caudal spine in the female tail, caudal bursa with rays 2 and 3 well developed, small dorsal lobe, and axis of orientation of synlophe subfrontal. It is likely that the monospecific genus Nesomystrongylus Durette-Desset, Lehtonen \& Haukisalmi, 2002 should be transferred to the Heligmosomidae.

Figs. 2a-c. - Types of symmetry of the caudal bursa.

a. Subsymmetrical: both lobes are of similar size and shape in relation to the axis of the dorsal ray, which passes through the sagittal axis of the worm. Ex: Pudica gamma (Travassos, 1918). After Travassos (1921), modified.

b. Dissymmetrical: one lobe is better developed in relation to the axis of the dorsal ray, which passes through the sagittal axis of the worm. Ex: Malvinema scapteromys (Suriano \& Navone, 1996). In this case, it involves the right lobe. After Digiani et al. (2003), modified.

c. Asymmetrical: the axis of the dorsal ray does not pass through the sagittal axis but is displaced to the right or left side of the worm. Both lobes may or may not have the same degree of development with respect to the axis of the dorsal ray. Ex: Malvinema victoriae Digiani, Sutton \& Durette-Desset (2003). In this case, the right lobe is slightly better developed. After Digiani et al. (2003), modified.

Fig. 2d. - Determination of the point of divergence of rays 2 to 6 from their common trunk.

The levels of divergence of rays 2 to 6 from the common trunk are indicated by the dotted lines, which are perpendicular to a main axis represented by a straight line passing through ray 4. Ex: Malvinema carolinae Digiani, Sutton \& Durette-Desset (2003). In the right lobe, ray 2 is the first (the most proximal ray) to diverge from the common trunk; the point of divergence of ray 3 is distal to that of ray 6. Rays 4 and 5 are the last to diverge. After Digiani et al. (2003), modified.

Scale-bars Figs. 2a-d: $50 \mu \mathrm{m}$.
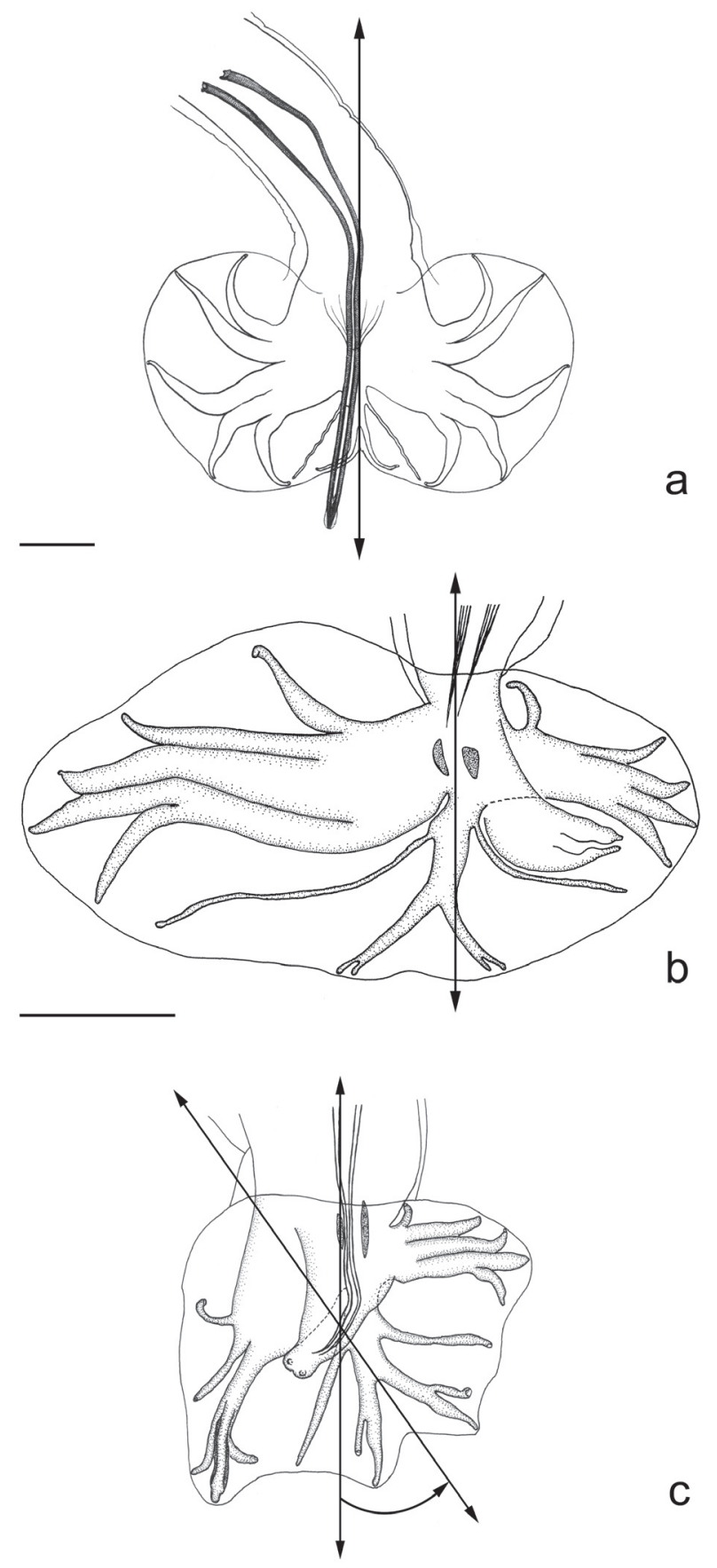

C

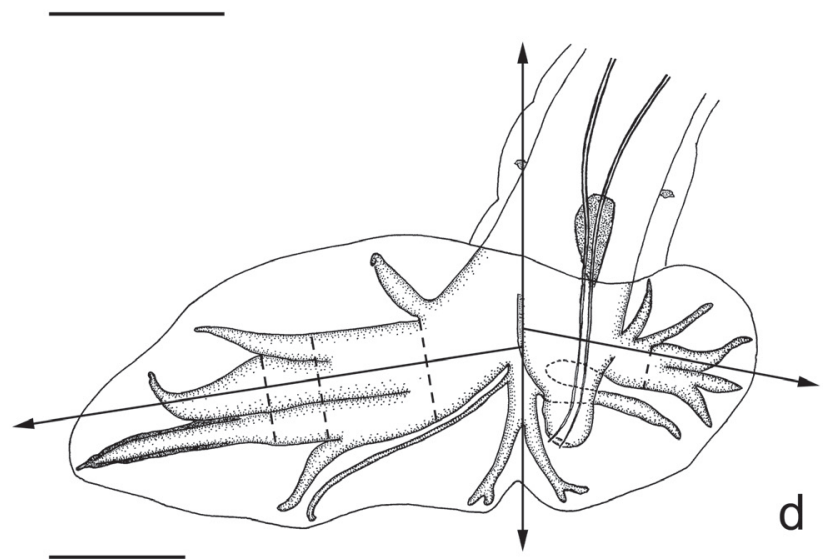



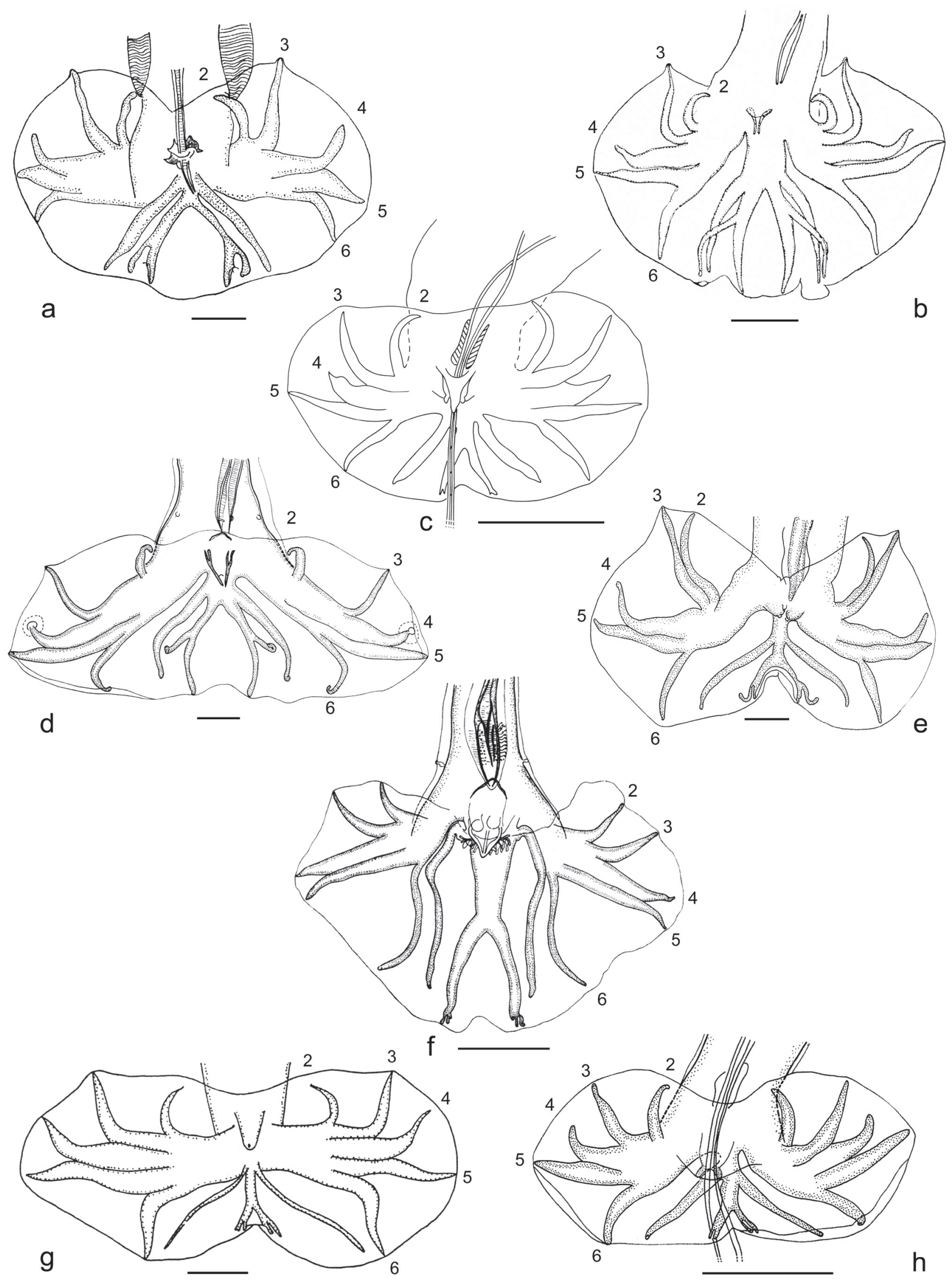


\section{RESULTS}

\section{DESCRIPTION OF THE PATTERNS}

- Basic and intermediary types

Type 2-3 (Fig. 3a)

- Rays 2 and 3 grouped, arising first and together from common trunk of rays 2 to 6 .

- Rays 2 and 3 grouped from base in V-shape.

- Rays 4 to 6 having common trunk.

- Divergence of rays 4, 5 and 6 at same level.

. Type 2-3 t 2-2-1 (e.g. type 2-3 tending to type 2-2-1, see Material \& Methods) (Fig. 3e)

- Rays 2 and 3 grouped, arising first and together from common trunk of rays 2 to 6 .

- Rays 4 to 6 having common trunk.

Figs. 3a-d. - Basic patterns. Scale-bars: $50 \mu \mathrm{m}$.

a. Type 2-3. Rays 2 and 3 are grouped, arising first and together from the common trunk of rays 2 to 6 ; rays 4 to 6 have a common trunk and diverge at the same level. Ex: Paraheligmonella interrogans (Lent \& Freitas, 1938). After Durette-Desset (1968b), modified.

b. Type 2-2-1. Rays 2 and 3 are grouped, arising first and together from the common trunk of rays 2 to 6 ; ray 6 arises at the same level as ray 3; rays 4 and 5 are the last to diverge. Ex: Heligmostrongylus crucifer (Travassos, 1943). After Travassos (1943), modified.

c. Type 1-3-1. Rays 2 and 6 arise first and at the same level from the common trunk of rays 2 to 6 ; rays 3 to 5 have a common trunk. Ex: Hypocristata tercera Durette-Desset \& Guerrrero, 2006. In this case ray 3 diverges first from the common trunk of rays 3 to 5 in the right lobe and at the same level as ray 5 in the left lobe. After Durette-Desset \& Guerrrero (2006), modified.

d. Type 1-4. Ray 2 arises first from the common trunk of rays 2 to 6 ; rays 3 to 6 have a long common trunk. Ex: Fuellebornema bocqueti (Durette-Desset, 1970a). In this case ray 3 diverges at the same level as ray 6 on the common trunk of rays 3 to 6 . After Durette-Desset (1970a), modified.

Figs. 3e-h. - Intermediary patterns. Scale-bars: $50 \mu \mathrm{m}$.

e. Type 2-3 t 2-2-1. Rays 2 and 3 are grouped, arising first and together from the common trunk of rays 2 to 6 ; rays 4 to 6 have a common trunk; ray 6 diverges close to the level of the divergence of ray 3 and proximally to that of rays 4 and 5. Ex: Neoheligmonella acomysi Durette-Desset \& Gibson, 1990. In this case rays 2 and 3 are apposed for much of their length. After Durette-Desset \& Gibson (1990), modified.

f. Type 2-2-1 t 1-3-1. Rays 2 and 6 arise first and at the same level from the common trunk of rays 2 to 6 ; rays 3 arise just distally to the level of divergence of rays 2 and 6 ; rays 4 and 5 are the last to diverge. Ex: Pudica pudica (Travassos, 1921). After Cassone \& Durette-Desset (1991), modified.

g. Type 1-3-1 t 1-4. Rays 2 arise first from the common trunk of rays 2 to 6 ; rays 6 arise slightly distally to the level of divergence of rays 2 and proximally to that of rays 3; rays 3 to 6 have a short common trunk. Ex: Spalacina yanchevi Biserkov, Durette-Desset \& Genov, 1995. After Biserkov et al. (1995), modified.

h. Type 2-2-1 t 1-4. Rays 2 arise first from the common trunk of rays 2 to 6; rays 3-6 have a short common trunk; rays 6 arise at the same level as rays 3; rays 4 and 5 are the last to diverge. Ex: Hypocristata anguillula (Durette-Desset, 1971). Ray 3 is still grouped with ray 2 since its extremity supports the ventral lobe. After Durette-Desset (1971), modified
- Divergence of ray 6 proximal to divergence of rays 4 and 5 and approximately at same level of divergence of ray 3 .

. Type 2-2-1 (Fig. 3b)

- Rays 2 and 3 grouped, arising first and together from common trunk of rays 2 to 6 .

- Ray 6 arising at the same level as ray 3 .

- Distal divergence of rays 4 and 5.

. Type 2-2-1 t 1-3-1 (Fig. 3f)

- Rays 2 and 6 arising first and at same level from common trunk of rays 2 to 6 .

- Ray 3 arising just distally to level of divergence of rays 2 and 6.

- Distal divergence of rays 4 and 5 .

. Type 1-3-1 (Fig. 3c)

- Rays 2 and 6 arising first and at same level from common trunk of rays 2 to 6 .

- Rays 3 to 5 having common trunk.

Type 1-3-1 t 1-4 (Fig. 3g)

- Ray 2 arising first from common trunk of rays 2 to 6 .

- Ray 6 arising slightly distally to level of divergence of ray 2 and proximally to level of divergence of ray 3 .

- Rays 3 to 6 having short common trunk.

. Type 1-4 (Fig. 3d)

- Ray 2 arising first from common trunk of rays 2 to 6 .

- Rays 3 to 6 having long common trunk.

. Type 2-2-1 t 1-4 (Fig. 3h)

- Ray 2 arising first from common trunk of rays 2 to 6 .

- Ray 6 arising at the same level as ray 3 .

- Rays 3 to 6 having short common trunk.

- Distal divergence of rays 4 and 5 .

Remarks

In the patterns where rays 2 and 3 are grouped, the grouping shows different types: rays 2 and 3 may be joined to a lesser (Fig. 3e) or greater extent (Fig. 4a) or having a V-shape with the branches separated to a lesser (Fig. 4b) or greater extent (Fig. 4c). In the latter case, rays 2 and 3 may be very distant from each other at their extremity, however both rays are all the same considered as grouped with rays 3 still supporting the ventral lobe. Such cases can be included in type 2-2-1 (Fig. 4c) or 2-2-1 t 1-4 (Fig. 3h), depending respectively on the presence or the absence of a short common trunk of rays 3 to 6 .

In type 1-3-1, on the common trunk of rays 3 to 5 , ray 3 can diverge proximally to (Fig. 3c, RL), at same level as (Fig. 3c, LL), or distally to (Fig. 4d, RL) ray 5.

In type $1-4$, on the common trunk of rays 3 to 6 , ray 3 can diverge proximally to (Fig. 3c, RL), at same level as (Fig. 3d, LL), or distally to (Fig. 4d, LL) ray 6.

- Atypical patterns

Seven atypical patterns were found among the Heligmonellidae: 

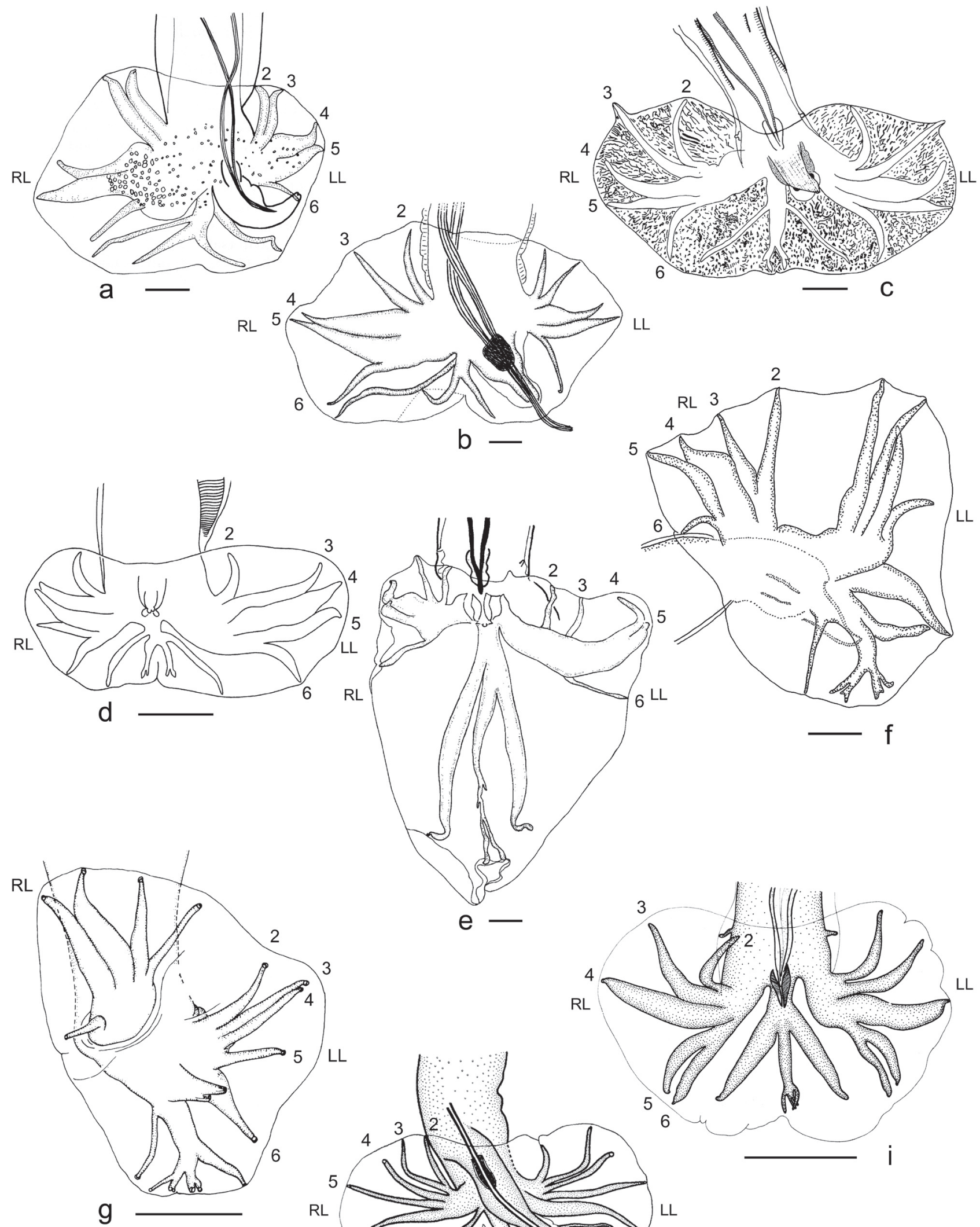

$\mathrm{RL}$
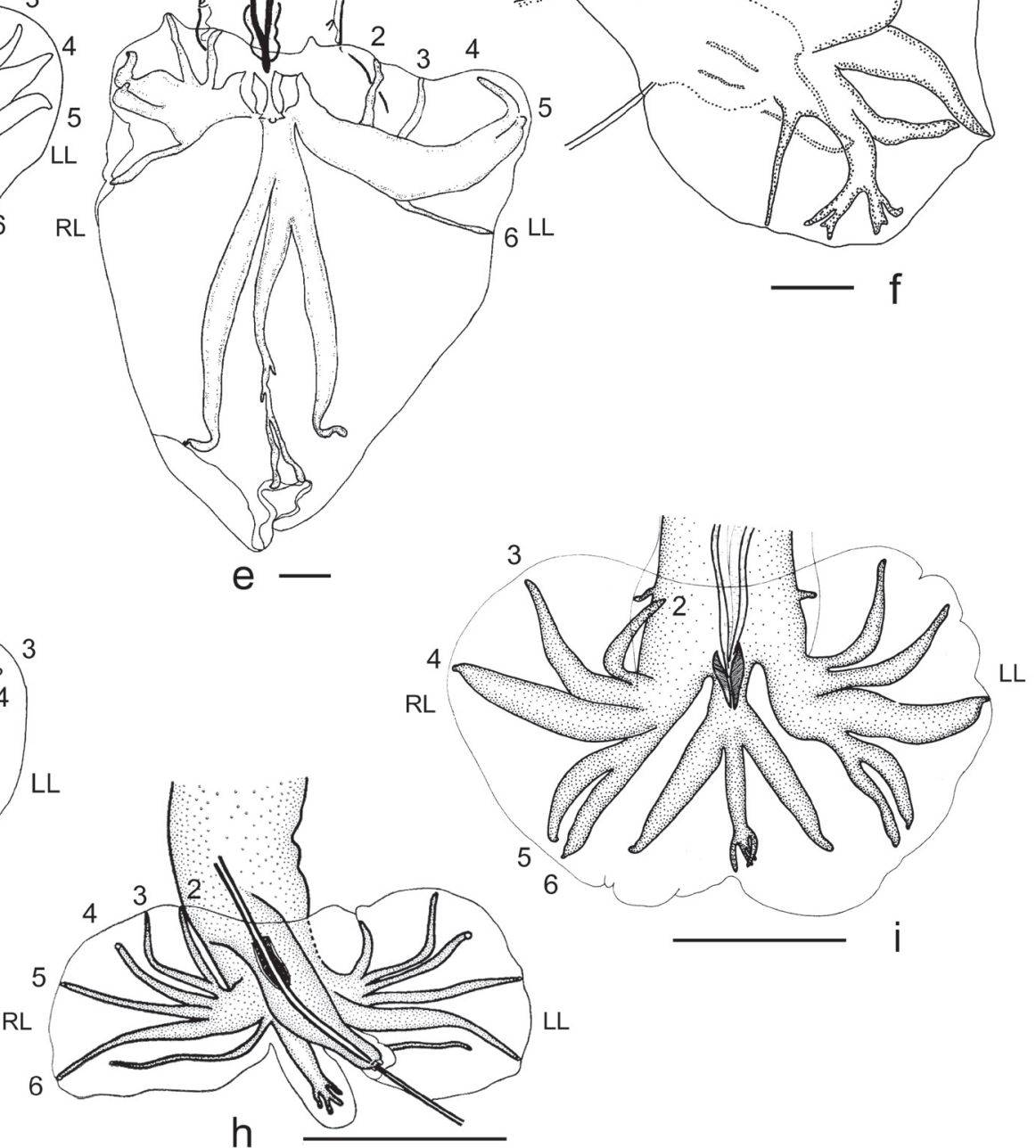
. Type 1-1-2-1 (Fig. 4e, LL)

- Ray 2 arising first from common trunk of rays 2 to 6 .

- Ray 3 completely separated and parallel to ray 2 , arising at the same level as ray 6 .

- Distal divergence of rays 4 and 5 .

Type 1-3-1 t 4-1 (Fig. 4f, RL)

- Ray 6 arising first from common trunk of rays 2 to 6 .

- Ray 2 arising just distally to level of divergence of ray 6.

- Rays 2 to 5 having very short common trunk.

. Type 4-1 (Fig. 4f, LL)

- Ray 6 arising first from common trunk of rays 2 to 6 .

Figs. 4a-d. - Variations on types 2-2-1, 1-3-1 and 1-4. Scale-bars: $50 \mu \mathrm{m}$. a. Type 2-2-1 with rays 2 and 3 apposed for much of their length. Ex: Stilestrongylus freitasi Durette-Desset, 1968a. After DuretteDesset (1968a), modified.

b. Type 2-2-1 with rays 2 and 3 grouped from the base in a narrow V-shape. Ex: right lobe of Stilestrongylus andalgala Digiani \& Durette-Desset, 2007. After Digiani \& Durette-Desset (2007), modified.

c. Type 2-2-1 with rays 2 and 3 grouped from the base in a wide V-shape. Ex: Carolinensis kinsellai (Durette-Desset, 1969). After Durette-Desset (1969), modified.

d. Type 1-3-1 with rays 3 diverging distally to rays 5 from the common trunk of rays 3 to 5. Ex: right lobe of Heligmonina wakelini Durette-Desset, Digiani, Mahlaba \& Behnké, 2007. After DuretteDesset et al. (2007), modified.

Figs. 4e-i. - Atypical patterns. Scale-bars: $50 \mu \mathrm{m}$.

e. Type 1-1-2-1. Rays 2 arise first from the common trunk of rays 2 to 6; rays 3 are completely separated and parallel to rays 2 and arise at the same level as rays 6; rays 4 and 5 are the last to diverge. Ex: left lobe of Cordicauda cordicauda (Durette-Desset, 1966). After Durette-Desset (1966), modified.

f. Type 1-3-1 t 4-1. Ray 6 arises first from the common trunk of rays 2 to 6 ; ray 2 arises just distally to the level of divergence of ray 6 and rays 2 to 5 have a short common trunk. Ex: right lobe of Nippostrongylus magnus (Mawson, 1961). Type 4-1. Ray 6 arises first from the common trunk of rays 2 to 6 and rays 2 to 5 have a long common trunk. Ex: left lobe of $N$. magnus. After Beveridge \& Durette-Desset (1992), modified.

g. Type 3-1-1. Rays 5 and 6 arise first but separately from the common trunk of rays 2 to 6 and rays 2 to 4 have a long common trunk. Ex: left lobe of Nippostrongylus marbaeniae Hasegawa \& Syafruddin, 1995. The right lobe shows a pattern of type 1-3-1 t 4-1. After Hasegawa \& Syafruddin (1995), modified.

h. Type 1-2-1-1. Ray 2 arises first from the common trunk of rays 2 to 6 ; rays 3 and 4 are grouped and rays 5 and 6 arise separately and at the same level as the group formed by rays 3 and 4 . Ex: left lobe of Sciuricola moreli (Gibbons, Durette-Desset \& Daynes, 1977). The right lobe shows a pattern of type 2-2-1. After DuretteDesset (1974), modified.

i. Type 1-2-2. Ray 2 arises first from the common trunk of rays 2 to 6 ; rays 3 and 4 are grouped; rays 5 and 6 have a short common trunk and arise at the same level as ray 2 and the group formed by rays 3 and 4. Ex: right lobe of Trichoslinstowia maseri DuretteDesset \& Vaucher, 1974. After Durette-Desset \& Vaucher (1974), modified. Type 2-1-2. Rays 2 and 3 are grouped and arise first from the common trunk of rays 2 to 6 ; ray 4 is isolated; rays 5 and 6 have a short common trunk and arise at the same level as ray 4 and the group formed by rays 2 and 3. Ex: left lobe of T. maseri. After Durette-Desset \& Vaucher (1974), modified.
- Rays 2 to 5 having long common trunk.

. Type 3-1-1 (Fig. 4g, LL)

- Rays 5 and 6 arising first but separated from common trunk of rays 2 to 6 .

- Rays 2 to 4 having long common trunk.

. Type 1-2-1-1 (Fig. 4h)

- Ray 2 arising first from common trunk of rays 2 to 6 . - Rays 3 and 4 grouped.

- Rays 5 and 6 arising separated and at same level as group formed by rays 3 and 4 .

Type 1-2-2 (Fig. 4i, RL)

- Ray 2 arising first from common trunk of rays 2 to 6 .

- Rays 3 and 4 grouped.

- Rays 5 and 6 having short common trunk, arising at the same level as ray 2 and group formed by rays 3 and 4 .

. Type 2-1-2 (Fig. 4i, LL)

- Rays 2 and 3 grouped and arising first from common trunk of rays 2 to 6 .

- Ray 4 isolated.

- Rays 5 and 6 having short common trunk, arising at the same level as ray 4 and group formed by rays 2 and 3 .

\section{EVOLUTIONARY INTERPRETATION OF THE PATTERNS}

Durette-Desset (1985) highlighted two evolutionary trends treating the Strongylida as a set: (1) reduction of the dorsal lobe (in the Rhabditida the tail of the male is vertically elongated) and (2) lengthening of rays 4 , as papillae 4 of the Rhabditida are close to the anus (see Osche 1958; Chabaud et al., 1970 for the homology between the papillae of the Rhabditida and the bursal rays of the Strongylida) (Figs. 5a, 5b). Therefore Durette-Desset (1985) suggested that a caudal bursa with a short dorsal lobe and long rays 4 should be considered as highly evolved. Though these trends occur in each type of bursa, in general, types 2-1-2 and 2-3 (among the five types of pattern recognized) were considered as basal types for two reasons: they are the closest to the pattern of the Rhabditida with a well developed dorsal lobe and short rays 4; and they are also present in all four suborders of the Strongylida. However, no further attempt was made to explain the other patterns from an evolutionary point of view. We propose the following interpretation (Fig. 5c).

In the Heligmonellidae the most basal pattern found is of type 2-3 (Fig. 3a). In this type, the dorsal lobe is relatively long as is ray 6 , which diverges distally from the common trunk of rays 4 to 6 .

The transition from type 2-3 to type 2-2-1 involves the migration of ray 6 towards the base of the trunk of rays 2 to 6 , as seen in the intermediary type 2-3 t 2-2-1 (Fig. 3e). In type 2-2-1 (Fig. 3b), ray 6 has achieved this migration and diverges from the common trunk at same level as rays 3 . 




a

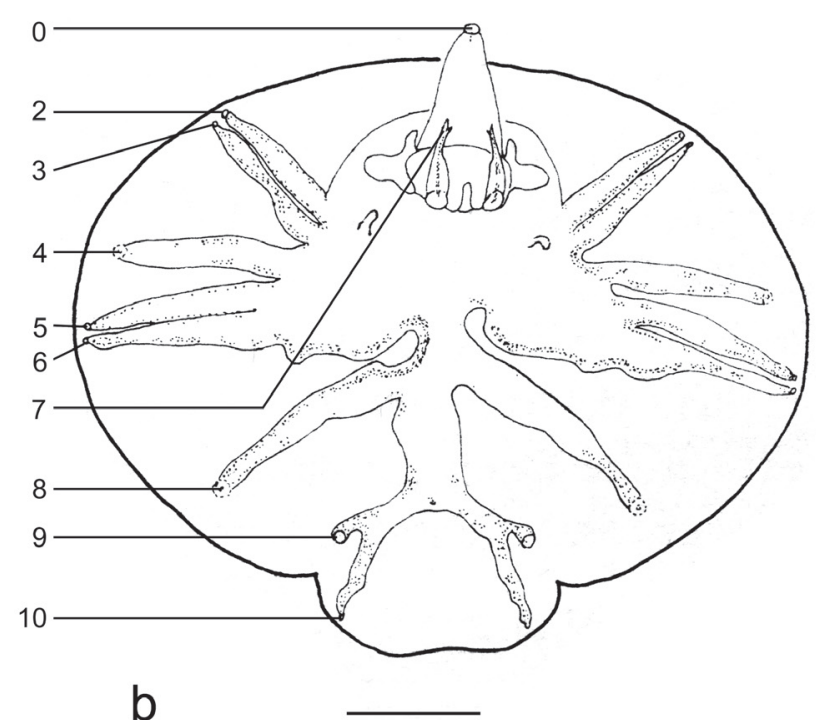

b

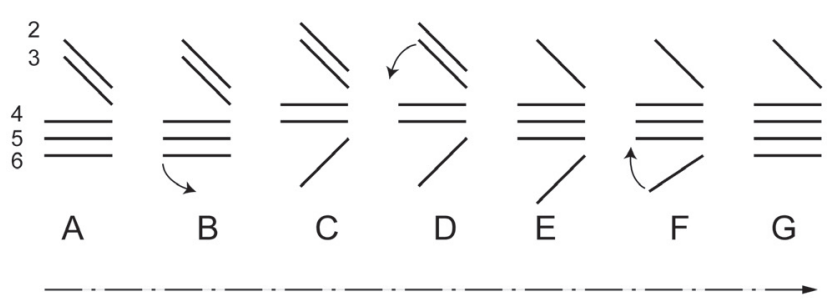

C
The transition from type 2-2-1 to type 1-3-1 involves a progressive migration of ray 3 towards ray 4 along with a progressive shortening of the dorsal lobe and ray 6 , as observed in the intermediary type $2-2-1 \mathrm{t} 1-3-$ 1 (Fig. 3f). In type 1-3-1 (Fig. 3c), the migration of ray 3 towards rays 4 is achieved, with the appearance of a common trunk of rays 3-5, and ray 6 diverges from this common trunk at same level as ray 2 .

The transition from type 1-3-1 to type 1-4 involves a distal migration of ray 6 , with the appearance of a common trunk of rays 3 to 6 , and a progressive lengthening of this trunk, as observed in the intermediary type 1-3-1 t 1-4 (Fig. 3g). In type 1-4 (Fig. 3d), only ray 2 arises first from the common trunk. This type of caudal bursa widens laterally and its width is greater than its length.

The evolutionary steps then seem to follow the direction: $2-3$ to $2-2-1$ to $1-3-1$ to $1-4$, which is consistent with the early interpretation by Durette-Desset (1985) with respect to the basal patterns and the caudal bursae in which the width is greater than the length. Several descriptions of caudal bursae, especially in species of Heligmonina where the pattern was described as being of type 1-4 tending to type 1-3-1 (see for example Diouf et al., 2005) are therefore inaccurate from an evolutionary point of view.

Some lobes may show a pattern of intermediary type 2-2-1 t 1-4 (Fig. 3h). This transition from type 2-2-1 involves the lengthening from the base of the set of rays 3-6 just after the divergence of ray 2, with the appearance of a short common trunk of rays 3 to 6 (intermediary type 2-2-1 t 1-4).

A particular 2-3 type was observed in some bursae or isolated lobes of the genera Srivastavanema (Singh, 1962) (Brevistriatinae) and Malvinema Digiani, Sutton \& Durette-Desset, 2003 (Nippostrongylinae). In these cases one or both lateral lobes show an arrangement

Figs. 5a-b. - Homology of the bursal rays of the Rhabditida and the Strongylida. Scale-bars: $50 \mu \mathrm{m}$.

a. Bursal rays of the Rhabditida sensu Osche (1958). Papillae 7 are fused with papillae 8. After Osche (1958), modified.

b. Bursal rays of the Strongylida sensu Chabaud et al. (1970). Papillae 7 are situated on the genital cone. After Chabaud et al. (1970), modified.

Fig. 5c. - Schematic representation of the bursal patterns of rays 2 to 6 showing the hypothetical evolutionary steps.

From the basal pattern of type $2-3$, the evolutionary steps follow the direction: $2-3$ tending to $2-2-1$ to $1-3-1$ to $1-4$ with the intermediary patterns: $2-3$ tending to $2-2-1,2-2-1$ tending to $1-3-1,1-3-1$ tending to $1-4$. Some lobes have a pattern of type $2-2-1$ t $1-4$.

A. Type 2-3. B. Type 2-3 t 2-2-1. C. Type 2-2-1. D. Type 2-2-1 t 1-3-1. E. Type 1-3-1. F. Type 1-3-1 t 1-4. G. Type 1-4. The small arrows indicate the transition from a type to another. The dotted arrow indicates the hypothetic evolutionary progress of the pattern of the caudal bursae. 
of rays 2 to 6 corresponding to a type 2-3, however the dorsal lobe is greatly reduced, the caudal bursa is laterally elongated and they are typically complementary with type 1-4. This means that in two species of Malvinema, M. carolinae Digiani, Sutton \& Durette-Desset, 2003 and M. victoriae Digiani, Sutton \& Durette-Desset, 2003, whereas one lobe is of type 2-3, the other lobe shows a pattern of type 1-4 (Figs. 2c, 2d); the remaining two species, M. scapteromys (Suriano \& Navone, 1996) and M. yagoi Digiani \& Durette-Desset, 2003, show the type 1-4; in two species of Srivastavanema, S. cynocephali Durette-Desset \& Purwaningsih, 1999 and S. yapi Durette-Desset \& Lim Boo Liat, 1975, both lobes are of type 2-3 whereas a third species $S$. bhagwansinghi Durette-Desset \& Lim Boo Liat, 1975 shows a type $1-4$ in both lobes. We thus consider this type 2-3 as different from that of the most basal species. It may be derived from the type 1-4 by the migration of ray 3 towards ray 2, whereas rays 4 to 6 still have a long common trunk.

- Atypical patterns

. Type 1-1-2-1 (Fig. 4e) is present in the left lobe of Cordicauda cordicauda (Durette-Desset, 1966) (Brevistriatinae). This type seems to have been derived from type $2-2-1$ by the isolation of ray 2 and short migration of ray 3 on the common trunk of rays 2 to 6 .

. Type 1-3-1 t 4-1 (Fig. 4f, RL) is present in the right lobes of Nippostrongylus magnus (Mawson, 1961) and N. marbaeniae Hasegawa \& Syafruddin, 1995 (Nippostrongylinae). The transition from type 1-3-1 to type 4-1 involves a distal migration of ray 2 towards ray 3, forming a short common trunk of rays 2 to 5 . Ray 6 is the most proximal ray to diverge from the common trunk of rays 2-6 and ray 2 arises just slightly distally to ray 6.

. Type 4-1 (Fig. 4f, LL) is present in both lobes of Nippostrongylus sembeli Hasegawa \& Tarore, 1995; and in the left lobes of $N$. magnus, $N$. rauschi Chabaud \& Desset, 1966 and N. typicus (Mawson, 1961). This type seems directly derived from type 1-3-1, involving a marked distal migration of ray 2 towards ray 3 . Ray 6 is the most proximal ray to diverge from the common trunk of rays $2-6$, and rays 2 to 5 form a long common trunk on which ray 2 arises distinctly distally.

. Type 3-1-1 (Fig. 4g, LL) is present in the left lobes of four species of Nippostrongylus: $N$. djumachani (Tenora, 1969), N. marbaeniae, N. rysavyi (Erhardova, 1959) and $N$. witenbergi Greenberg, 1972. It seems directly derived from type 4-1 by the migration of ray 5 from its base towards ray 6 . Ray 5 diverges from the common trunk at the same level as ray 6 and there is persistence of the common trunk of rays 2 to 4 .

Type 1-2-1-1 (Fig. 4h, LL) is present in the left lobes of Sciuricola dremomys (Yen, 1973) and S. moreli
(Gibbons, Durette-Desset \& Daynes, 1977) (Heligmonellinae). It seems directly derived from type 1-3-1 by the migration (but not apposition) of ray 5 towards ray 6 , with persistence of the group formed by rays 3 and 4 .

. Type 1-2-2 (Fig. 4i, RL) is present in the right lobe of Tricholinstowia maseri Durette-Desset \& Vaucher, 1974 (Heligmonellinae). It seems to be derived from type 13-1 (present in the other species of Tricholinstowia) by the migration of ray 5 towards ray 6. Type 2-1-2 (Fig. $4 \mathrm{i}, \mathrm{LL})$ is present in the left lobe of the same species. It could be derived from type 1-2-2 by the migration of ray 3 towards ray 2 , along with the absence of common trunk between rays 3 and 4 .

A pattern of type 2-1-2 is characteristic of the Molineoidea. However, type 2-1-2 of the Molineoidea is interpreted as a basal pattern, also characterized by short rays 4, whereas the pattern found in T. maseri, with long rays 4 , is considered as derived from a 1-31 type. In this case, we consider the presence of this type in one lobe of Heligmonellidae as a convergence.

\section{CRITERIA UTILIZED FOR THE CHARACTERIZATION of the CAUDAl BURSAE of the Heligmonellidae}

- Type of symmetry (definition and examples above) At the specific level, a caudal bursa may be subsymmetrical (CB SS); dissymmetrical with right lobe larger (CB DS RL+); dissymmetrical with left lobe larger (CB DS LL+); asymmetrical (CB AS); asymmetrical with right lobe larger (CB AS RL+); asymmetrical with left lobe larger (CB AS LL+). At the generic level, we consider that a given genus may be characterized by the type of symmetry most frequently found among the species belonging to this genus.

\section{- Evolutionary comparison between lobes}

As mentioned above, a species can have the same or a different pattern in both latero-ventral lobes. On the other hand, as seen above, the different patterns may be interpreted from an evolutionary point of view. This determines three types of "evolutionary ratio" between both lateral lobes ("right/left ratio") in a caudal bursa: (1) the same pattern in both lobes; (2) the pattern of the right lobe is derived with respect to that of the left lobe ("RL derived"); or (3) the pattern of the left lobe is derived with respect to that of the right lobe ("LL derived").

\section{- Characteristic pattern}

Within a given genus the bursal pattern usually varies among the species. Moreover, as seen immediately above, most species have a different pattern in each lobe. This means that in some genera we can find several different patterns. However it seems possible to choose one or two characteristic patterns for each 
genus. The characteristic pattern is determined by the type most frequently found, which is here interpreted as the most frequent basic type plus the contiguous intermediary types. For example, for the genus Sciurodendrium Durette-Desset, 1971 (Pudicinae, seven species) we propose that the characteristic pattern is of type 2-2-1 because amongst the 11 treatable lobes, four are of type 2-2-1, three of type 2-3 t 2-2-1, and two of type 2-2-1 t 1-3-1. Some genera may have two characteristic patterns. For example in Heligmonina (Nippostrongylinae, 27 species) two characteristic patterns are proposed: 1-3-1 and 1-4; type 1-3-1 being the most frequent in the right lobe and type 1-4 in the left lobe (21 and 19 lobes respectively).

\section{Characterization OF THE CAUDAL BURSAE OF THE GENERA OF THE HELIGMONELLIDAE}

- Heligmonellidae (Skrjabin \& Schikhobalova, 1952, tribe) Durette-Desset, 1971 (four subfamilies, 56 genera, 329 species; for each genus, in parentheses, number of species examined / number of species described)

- Heligmonellinae (Skrjabin \& Schikhobalova, 1952, tribe) Durette-Desset \& Chabaud, 1977 (six genera, 22 species)

. Heligmonella Mönnig, 1927 (3/4)

CB SS (2 spp.) or CB DS RL+ (1 sp.). CB with the same pattern in both lobes (2 spp.) or with LL derived (1 sp.). Patterns observed: 2-3 t 2-2-1, 2-2-1, 1-4. Characteristic pattern: 2-2-1.

. Paraheligmonella Durette-Desset, 1971 (4/5)

CB SS. CB with same pattern in both lobes (3 spp.) or with RL derived (1 sp.). Patterns observed: $2-3,2-3 \mathrm{t}$ 2-2-1, 2-2-1, atypical 2-2-1 t 4-1. Characteristic pattern: 2-2-1.

Remark: the species Parabeligmonella cubaensis (Pérez Vigueras, 1943), with the pattern 1-4 in both lobes was considered with reservations as belonging to Paraheligmonella (Digiani et al., 2009).

. Sciuricola Durette-Desset, 1983 (2/2)

CB SS. CB with different patterns in both lobes (1 sp.). Patterns observed: 2-3 t 2-2-1, atypical 1-2-1-1. Characteristic pattern: the data are insufficient to choose a characteristic pattern but two characters of the $\mathrm{CB}$ shared by both species are rays 4 and 5 separated from base and dorsal lobe distinct.

. Tricholinstowia Travassos, 1937 (8/8)

CB SS (6 spp.) or CB DS LL+ (1 sp.), type of symmetry unknown in $1 \mathrm{sp}$. CB with the same pattern in both lobes (4 spp.) or with RL derived (1 sp.) or with LL derived ( $1 \mathrm{sp}$.), right/left ratio unknown in $2 \mathrm{spp}$. Patterns observed: $2-3$ t 2-2-1, 2-2-1, 2-2-1 t 1-3-1, 1-3-1, atypical 1-2-2 and 2-1-2. Characteristic pattern: 1-3-1; rays 5 and 6 pincer-shaped.
Remark: only the right lobe is treatable in T. mogera (Sadovskaja, 1952) and T. morenishi (Cameron \& Parnell, 1933).

Trichotravassosia Lent \& Freitas, 1938 (2/2)

CB SS. CB with the same pattern in both lobes. Patterns observed: 2-2-1 t 1-4, atypical 2-2-1 t 4-1. Characteristic pattern: 2-2-1.

Remark: in T. capromydis Baruš \& Rysavý, 1967 only the right lobe is treatable, showing an atypical pattern of type 2-2-1 tending to 4-1.

. Xericola Durette-Desset, 1974 (1/1)

CB SS. CB with the same pattern in both lobes. Patterns observed: 2-2-1 t 1-4. Characteristic pattern: 2-2-1.

- Brevistriatinae Durette-Desset, 1971 [12 genera (11 treated), 66 species]

. Brevistriata Travassos, 1937 (3/4)

$\mathrm{CB}$ SS. $\mathrm{CB}$ with the same pattern in both lobes. Patterns observed: 2-3 t 2-2-1, 2-2-1. Characteristic pattern: 2-2-1.

Remark: the caudal bursa of B. fukiensis Wang, Zao \& Chen, 1978, is not included as the published illustration is not of a fully opened bursa.

. Calypsostrongylus Schmidt, Myers \& Kuntz, 1967 $(7 / 7)$

CB SS (5 spp.) or CB DS RL+ (2 spp.). CB with the same pattern in both lobes ( 5 spp.) or with LL derived (2 spp.). Patterns observed: $2-3$ t 2-2-1, 2-2-1, 2-2-1 t 1-4. Characteristic pattern: 2-2-1.

. Cordicauda Durette-Desset, 1971 (5/5)

CB DS LL+ (3 spp.) or CB SS (2 spp.). CB with the same pattern in both lobes (3 spp.) or LL derived (2 spp.). Patterns observed: $2-3$ t 2-2-1, 2-2-1, 1-4. Characteristic pattern: 2-2-1.

. Fissicauda Durette-Desset \& Krishnansamy, 1976 $(6 / 6)$

CB SS (3 spp.) or CB DS LL+ (2 spp.) or CB DS RL+ (1 sp.). CB with the same pattern in both lobes (3 spp.) or with RL derived (3 spp.). Patterns observed: 2-3 t 2-2-1, 2-2-1, 2-2-1 t 1-3-1, 1-3-1. Characteristic pattern: 2-2-1.

. Kuala Durette-Desset \& Krishnansamy, 1976 (2/2) CB SS. CB with the same pattern in both lobes. Pattern observed: atypical type 1-2-2.

. Lagostrongylus Fukumoto, Kamiya \& Ohbayashi, $1986(3 / 3)$

CB SS. CB with the same pattern in both lobes. Patterns observed: $2-3$ t 2-2-1. Characteristic pattern: 2-3 t 2-2-1.

. Macrostrongylus Ow-Yang, Durette-Desset \& Ohbayashi, $1983(2 / 2)$

CB SS. CB with the same pattern in both lobes. Patterns observed: 2-3 t 2-2-1, 2-2-1. Characteristic pattern: 2-2-1. 
. Metheligmonella Durette-Desset, 1971 (2/2)

CB SS. CB with the same pattern in both lobes. Patterns observed: $2-3$ t 2-2-1. Characteristic pattern: 2-3 t 2-2-1.

. Paraheligmonina (Ortlepp, 1939) (27/28)

CB SS (12 spp.) or with a slight left (8 spp.) or right (7 spp.) dissymmetry. CB with the same pattern in both lobes (18 spp.) or with LL derived (7 spp.) or with RL derived (2 spp.). Patterns observed: 2-3 t 2-2-1, 2-2-1, 1-3-1, 1-4, atypical 2-2-1 t $4-1$ and 4-1. Characteristic patterns: 2-2-1, 1-3-1.

Remark: the caudal bursa of P. trifurcata (Baylis, 1928) is not included as the published illustration is not of a fully opened bursa.

. Quentinstrongylus Durette-Desset, 1969 (1/1)

CB SS. CB with the same pattern in both lobes. Patterns observed: 1-3-1. Characteristic pattern: 1-3-1.

. Srivastavanema (Singh, 1962) (3/5)

CB SS. CB with the same pattern in both lobes. Patterns observed: secondary $2-3$, and $1-4$. Characteristic pattern: 1-4.

- Pudicinae (Skrjabin \& Schikhobalova, 1952, tribe) Durette-Desset, 1971 (nine genera, 44 species)

. Acanthostrongylus Travassos, 1937 (1/1)

CB SS. CB with the same pattern in both lobes. Pattern observed: 1-4. Characteristic pattern: 1-4.

. Durettestrongylus Guerrero, 1982 (2/3)

$\mathrm{CB}$ SS. CB with the same pattern in both lobes. Patterns observed: 2-2-1. Characteristic pattern: 2-2-1.

.Freitastrongylus Gonçalves, Pinto \& Durette-Desset $(1 / 1)$

CB SS. CB with the same pattern in both lobes. Pattern observed: 1-4. Characteristic pattern: 1-4.

. Fuellebornema Travassos \& Darriba, 1929 (6/7)

CB SS. CB with the same pattern in both lobes. Pattern observed: 1-4. Characteristic pattern: 1-4.

Remark: the caudal bursa of $F$. almeidai Travassos, 1937 is not included as the published illustration is not of a fully opened bursa.

. Heligmostrongylus Travassos, 1917 (9/9)

CB SS. CB with the same pattern in both lobes (8 spp.) or with LL derived (1 sp.). Patterns observed: 2-2-1, 2-2-1 t 1-3-1, 1-3-1. Characteristic pattern: 2-2-1.

. Justinema R'Kha \& Durette-Desset, 1991 (3/3)

CB SS. CB with RL derived (2 spp.) or with the same pattern in both lobes (1 sp.). Patterns observed: 2-2-1, 2-2-1 t 1-3-1. Characteristic pattern: 2-2-1.

. Pseudoheligmosomum Travasssos, 1937 (1/1)

CB AS LL+. CB with the same pattern in both lobes. Pattern observed: 2-3. Characteristic pattern: 2-3.

. Pudica Travassos \& Darriba, 1929 (12/12)

CB SS. CB with the same pattern in both lobes (11 spp.) or with RL derived (1 sp.). Patterns observed:
2-3 t 2-2-1, 2-2-1, 2-2-1 t 1-3-1, 1-3-1, 1-4. Characteristic patterns: $2-2-1,1-3-1$.

. Sciurodendrium Durette-Desset, 1971 (6/7)

CB SS. CB with LL derived (3 spp.) or with the same pattern in both lobes ( $2 \mathrm{spp}$.), right/left ratio unknown in 1 sp. Patterns observed: $2-3$ t 2-2-1, 2-2-1, 2-2-1 t 1-3-1, 1-3-1. Characteristic pattern: 2-2-1.

Remarks: the caudal bursa of $S$. aripense (Baylis, 1947) is not included as the published illustration is not of a fully opened bursa. Only the right lobe is treatable in S. bravohollisae Falcón-Ordaz \& Lamothe-Argumedo, 2006.

- Nippostrongylinae Durette-Desset, 1971 (29 genera, 197 species)

. Bunomystrongylus Hasegawa \& Mangali, 1996 (2/2) CB DS RL+ (1 sp.) and CB DS LL+ (1 sp.). CB with RL derived. Patterns observed: 2-3 t 2-2-1, 2-2-1, 1-3-1, 1-4. No characteristic pattern.

Carolinensis (Travassos, 1937) (12/12)

CB SS (7 spp.) or CB DS LL+ (4 spp.) or CB DS LL+ (1 sp.). CB with the same pattern in both lobes (9 spp.) or with RL derived (1 sp.) or with LL derived (1 sp.), right/left ratio unknown in one species. Patterns observed: $2-3$ t 2-2-1, 2-2-1, 2-2-1 t 1-3-1, 1-3-1, 1-3-1 t 1-4, 1-4. Characteristic pattern: 2-2-1.

Remark: only the right lobe is treatable in C. eothenomysi Asakawa, Kamiya \& Ohbayashi, 1986 and C. buebuetlana Falcón-Ordaz \& Sanabria Espinosa, 1996, the left lobe being not spread out.

Euzetoda Elias \& Durette-Desset, 2003 (1/1)

CB SS. CB with the same pattern in both lobes. Pattern observed: $2-3$ t 2-2-1. Characteristic pattern: $2-3$ t 2-2-1.

Guerrerostrongylus Sutton \& Durette-Desset, 1991 (2/2) CB SS. CB with the same pattern in both lobes. Patterns observed: 1-3-1. Characteristic pattern: 1-3-1.

. Hasanuddinia Hasegawa \& Syafruddin, 1994 (1/1) CB SS. CB with RL derived. Patterns observed: 2-2-1 t 1-3-1, 2-2-1 t 1-4. Characteristic pattern: 2-2-1.

. Hassalstrongylus Durette-Desset, 1971 (13/14)

CB SS (6 spp.) or DS RL+ (6 spp.) or DS LL+ (1 sp.). $\mathrm{CB}$ with the same pattern in both lobes $(9 \mathrm{spp}$.) or RL derived (2 spp.) or LL derived (2 spp.). Patterns observed: $2-3$ t 2-2-1, 2-2-1, 2-2-1 t 1-3-1, 1-3-1, 1-4. Characteristic patterns: 1-4 (type species), 2-2-1, 1-3-1. Remark: the caudal bursa of $H$. mazzai Freitas, Lent \& Almeida, 1937 is not included as the published illustration is not of a fully opened bursa.

. Heligmonina Baylis, 1928 (24/26)

CB DS LL+. CB with LL derived (21 spp.) or with the same pattern in both lobes (3 spp.). Patterns observed: 1-3-1, 1-3-1 t 1-4, 1-4. Characteristic patterns: 1-3-1 on right lobe, $1-4$ on left lobe. 
Remarks: the caudal bursa of $H$. oenomyos Baylis, 1928 is not illustrated and therefore untreatable. The left lobe of H. cricetomyos Baylis, 1928 is typical of the genus Heligmonina i.e. of type 1-4, but the right lobe is atypical with a type 2-2-1 not retained in the patterns observed.

\section{. Heligmonoides Baylis, 1928 (12/12)}

CB DS LL+. CB with the same pattern in both lobes (6 spp.) or with RL derived (3 spp.) or LL derived (3 spp.). Patterns observed: $2-3$ t 2-2-1, 2-2-1, 2-2-1 t 13-1, 1-3-1, 1-4. Characteristic pattern: 2-2-1.

Hypocristata Durette-Desset, 1971 (3/3)

CB SS (2 spp.) or DS RL+ (1 sp.). CB with the same pattern in both lobes (1 sp.) or with RL derived (1 sp.) or with LL derived (1 sp.). Patterns observed: 2-2-1, 2-2-1 t 1-4, 2-2-1 t 1-3-1, 1-3-1. Characteristic pattern: 1-3-1.

. Malaistrongylus Ow-Yang, Durette-Desset \& Ohbayashi, $1983(1 / 1)$

CB SS. CB with the same pattern in both lobes. Pattern observed: 2-2-1. Characteristic pattern: 2-2-1.

. Malvinema Digiani, Sutton \& Durette-Desset, 2003 (4/4)

CB DS RL+ (3 spp.) or CB AS RL+ (1 sp.). CB with the same pattern in both lobes ( $2 \mathrm{spp}$.) or with RL derived (1 sp.) or with LL derived (1 sp.). Patterns observed: 1-4, secondary 2-3. Characteristic pattern: 1-4.

. Mammanidula Sadovskaja, 1952 (3/5)

CB AS RL+ (2 spp.) or CB SS (1 sp.). CB with LL derived (2 spp.) or RL derived (1 sp.). Patterns observed: 2-3, $2-3$ t 2-2-1, 2-2-1. Characteristic pattern: 2-2-1.

Remark: the caudal bursae of $M$. melomyos (Mawson, 1961) and M. siamensis Ohbayashi \& Vajrasthiva, 1983 are not included as the published illustrations are not of fully opened bursae.

. Mawsonema Smales \& Heinrich, 2010 (1/1)

CB SS. CB with the same pattern in both lobes. Pattern observed: 2-3. Characteristic pattern: 2-3.

. Maxomystrongylus Hasegawa \& Syafruddin, 1997 $(2 / 2)$

CB DS LL+. CB with the same pattern in both lobes (1 sp.) or with RL derived (1 sp.). Patterns observed: 2-3, 2-3 t 2-2-1, 2-2-1. Characteristic pattern: 2-2-1.

. Melomystrongylus Smales, 2009 (2/2)

CB DS LL+ or CB DS RL+. CB with RL derived (1 sp.), right/left ratio unknown in one species. Patterns observed: 2-3, 1-3-1. Characteristic pattern: 2-3.

Remark: only the left lobe of $M$. sepikensis Smales, 2009 is illustrated and treatable.

. Montistrongylus Smales \& Heinrich, 2010 (1/1)

CB DS RL+. CB with RL derived. Patterns observed:

2-3 t 2-2-1, 2-2-1. Characteristic pattern: 2-2-1.
. Neoheligmonella Durette-Desset, 1971 (21/23)

CB SS. CB with the same pattern in both lobes (for at least 12 spp.) or with RL derived (for at least 7 spp.), right/left ratio unknown in 2 spp. Patterns observed: 2-3, 2-3 t 2-2-1, 2-2-1. Characteristic pattern: 2-3 t 2-2-1. Remarks: the caudal bursa of $N$. affinis (Baylis, 1928) is not treatable since it is not illustrated in the original description. Only the right lobe is treatable in N. impudica (Baylis, 1928) and N. moennigi (Baylis, 1928). N. lemniscomysi (Durette-Desset, 1970) is the only species having a caudal bursa with a right lobe larger and with the same pattern (1-3-1) in both lobes. On the other hand, its synlophe is also very different from that of the remaining species in the genus. It is likely that this species belongs to a different genus and it is not treated herein.

. Nippostrongylus Lane, 1923 (9/9)

CB AS RL+ (6 spp.) or CB DS RL+ (3 spp.). CB with LL derived. Patterns observed: 1-3-1, 1-3-1 t 1-4, 1-31 t 4-1, 4-1, 3-1-1. Characteristic patterns: 1-3-1 and derived atypical 4-1 on right lobe; atypical 4-1 and derived atypical 3-1-1 on left lobe.

Odilia Durette-Desset, 1973 (18/19)

CB SS (8 spp.) or DS RL+ (3 spp.) or DS LL+ (2 spp.), symmetry unknown in $5 \mathrm{spp}$. CB with same pattern in both lobes (at least 8 spp.) or with RL derived (at least 3 spp.), right/left ratio unknown in 5 spp. Patterns observed: 2-3, 2-3 t 2-2-1, 2-2-1, 2-2-1 t 1-3-1, 2-2-1 t 1-4, 1-3-1, 1-3-1 t 1-4, 1-4. Characteristic patterns: 2-2-1, 1-4. Remarks: the caudal bursa of O. polyrhabdote (Mawson, 1961) is not included as the published illustration is not of a fully opened bursa. Only one lobe is treatable in $O$. brachybursa (Mawson, 1961), O. implexa Smales, 2008, O. moatensis (Hasegawa, Miyata \& Syafruddin, 1999), O. similis Smales, 2009 and O. uromyos (Mawson, 1961).

. Orientostrongylus Durette-Desset, 1970 (7/8)

CB SS. CB with the same pattern in both lobes (6 spp.) or with LL derived (1 sp.). Patterns observed: $2-3,2-3$ t 2-2-1, 2-2-1. Characteristic pattern: 2-2-1.

Remark: the caudal bursa of $O$. siamensis Ohbayashi \& Kamiya, 1980 is not included as the published illustration is not of a fully opened bursa.

Paraheligmonelloides Fukumoto, Kamiya \& Suzuki, $1980(9 / 9)$

CB DS LL+ (4 spp.) or CB DS RL+ (3 spp) or CB SS (2 spp.). CB with the same pattern in both lobes. Patterns observed: $2-3,2-3$ t 2-2-1, 2-2-1, 1-4. Characteristic patterns: $2-2-1,1-4$.

Remark: the caudal bursa of $P$. singauwaensis Smales, 2009 is treated from its redescription (Smales \& Heinrich, 2010).

. Parasabanema Smales \& Heinrich, 2010 (1/1)

CB SS. CB with the same pattern in both lobes. Pattern observed: 2-2-1. Characteristic pattern: 2-2-1. 
. Rattustrongylus Ow-Yang, Durette-Desset \& Ohbayashi, $1983(2 / 2)$

CB SS (1 sp.) or CB DS LL+ (1 sp.). CB with the same pattern in both lobes. Patterns observed: 2-2-1, 2-2-1 t 1-3-1. Characteristic pattern: 2-2-1.

. Sabanema Ow-Yang, Durette-Desset \& Ohbayashi, $1983(4 / 5)$

CB DS RL+ (3 spp.) or CB SS (1 sp.). CB with the same pattern in both lobes (2 spp.) or with RL derived (1 sp.) or with LL derived (1 sp.). Patterns observed: 2-3 t 2-2-1, 2-2-1. Characteristic pattern: 2-2-1.

Remark: the caudal bursa of $S$. kepongi Ow Yang, Durette-Desset \& Ohbayashi, 1983 is not included as the published illustration of the bursa is not of a fully opened bursa.

. Spalacina Biserkov, Durette-Desset \& Genov, 1995 (3/3) CB SS (2 spp.) or DS LL+ (1 sp.). CB with the same pattern in both lobes (at least $2 \mathrm{spp}$.), right/left ratio unknown in one species. Patterns observed: 1-3-1 t 1-4, 1-4. Characteristic pattern: 1-4.

Remark: only the right lobe is treatable in $S$. spalacis (Sharpilo, 1973) the left lobe being not spread out.

. Stilestrongylus Freitas, Lent \& Almeida, 1937 (24/25) CB DS RL+ (21 spp.) or CB SS (3 spp.). CB with RL

\begin{tabular}{lccc}
\hline \multicolumn{1}{c}{ Genus } & $\begin{array}{c}\text { Characteristic } \\
\text { symmetry }\end{array}$ & $\begin{array}{c}\text { Right/left } \\
\text { ratio }\end{array}$ & $\begin{array}{c}\text { Characteristic } \\
\text { pattern }\end{array}$ \\
\hline Heligmonella & CB SS & Same pattern & $2-2-1$ \\
Parabeligmonella & CB SS & Same pattern & $2-2-1$ \\
Sciuricola & CB SS & LL atypical & - \\
Tricholinstowia & CB SS & Variable & $1-3-1$ \\
Trichotravassosia & CB SS & Same pattern & $2-2-1$ \\
Xericola & CB SS & Same pattern & $2-2-1$ \\
\hline
\end{tabular}

CB SS: caudal bursa subsymmetrical. LL: left lobe of caudal bursa. Table I. - Synopsis of the caudal bursa in the Heligmonellinae.

\begin{tabular}{lccc}
\hline \multicolumn{1}{c}{ Genus } & $\begin{array}{c}\text { Characteristic } \\
\text { symmetry }\end{array}$ & $\begin{array}{c}\text { Right/left } \\
\text { ratio }\end{array}$ & $\begin{array}{c}\text { Characteristic } \\
\text { pattern }\end{array}$ \\
\hline Brevistriata & CB SS & Same pattern & $2-2-1$ \\
Calypsostrongylus & CB SS & Same pattern & $2-2-1$ \\
Cordicauda & Variable & Variable & $2-2-1$ \\
Fissicauda & Variable & Variable & $2-2-1$ \\
Kuala & CB SS & Same pattern & $1-2-2$ \\
Lagostrongylus & CB SS & Same pattern & $2-3$ t 2-2-1 \\
Macrostrongylus & CB SS & Same pattern & $2-2-1$ \\
Metheligmonella & CB SS & Same pattern & $2-3$ t 2-2-1 \\
Paraheligmonina & Variable & Variable & $2-2-1,1-3-1$ \\
Quentinstrongylus & CB SS & Same pattern & $1-3-1$ \\
Srivastavanema & CB SS & Same pattern & $1-4$ \\
\hline
\end{tabular}

CB SS: caudal bursa subsymmetrical.

Table II. - Synopsis of the caudal bursa in the Brevistriatinae. derived (11 spp.) or with the same pattern in both lobes (10 spp.) or with LL derived (3 spp.). Patterns observed: $2-3$ t 2-2-1, 2-2-1, 1-3-1, 1-4. Characteristic patterns: $2-2-1,1-4$.

Remark: the caudal bursa of $S$. peromysci Falcón-Ordaz \& Sanabria-Espinoza, 1999 is not included as the published illustration is not of a fully opened bursa.

. Suttonema Digiani \& Durette-Desset, 2003 (1/1)

CB DS RL+. CB with the same pattern in both lobes. Pattern observed: 1-4. Characteristic pattern: 1-4.

. Trichofreitasia Sutton \& Durette-Desset, 1991 (1/1) CB SS. CB with the same pattern in both lobes. Pattern observed: 2-2-1. Characteristic pattern: 2-2-1.

. Yatinema Asakawa \& Ohbayashi, 1985 (2/2)

CB SS (1 sp.) or CB DS RL+ (1 sp.). CB with RL derived (1 sp.), right/left ratio unknown in one species. Patterns observed: 2-2-1 t 1-4, 1-3-1. Characteristic pattern: 2-2-1.

Remark: only the right lobe of $Y$. siamensis Asakawa, Kamiya \& Ohbayashi, 1986 is treatable, the left lobe being not spread out.

Based on the elements considered above, the four subfamilies may be synthetically characterized as follows: the Heligmonellinae by a subsymmetrical caudal bursa, with the same pattern in both lobes, and a characteristic pattern of type 2-2-1 (Table I); the Brevistriatinae by a predominantly subsymmetrical caudal bursa, a right/left ratio which is variable but with predominantly the same pattern in both lobes, and several types of pattern with a predominance of the characteristic type 2-2-1 (Table II); the Pudicinae by a subsymmetrical caudal bursa, a right/left ratio which is variable but with predominantly the same pattern in both lobes, and several types of patterns with a predominance of characteristic types 2-2-1 and 1-4 (Table III); the Nippostrongylinae by a caudal bursa of variable symmetry, a right/left ratio which

\begin{tabular}{lccc}
\hline \multicolumn{1}{c}{ Genus } & $\begin{array}{c}\text { Characteristic } \\
\text { symmetry }\end{array}$ & $\begin{array}{c}\text { Right/left } \\
\text { ratio }\end{array}$ & $\begin{array}{c}\text { Characteristic } \\
\text { pattern }\end{array}$ \\
\hline Acanthostrongylus & CB SS & Same pattern & $1-4$ \\
Durettestrongylus & CB SS & Same pattern & $2-2-1$ \\
Freitastrongylus & CB SS & Same pattern & $1-4$ \\
Fuellebornema & CB SS & Same pattern & $1-4$ \\
Heligmostrongylus & CB SS & Same pattern & $2-2-1$ \\
Justinema & CB SS & Variable & $2-2-1$ \\
Pseudobeligmosomum & CB DS LL+ & Same pattern & $2-3$ \\
Pudica & CB SS & Same pattern & $2-2-1,1-3-1$ \\
Sciurodendrium & CB SS & Variable & $2-2-1$ \\
\hline
\end{tabular}

CB SS: caudal bursa subsymmetrical. CB DS LL+: caudal bursa dissymmetrical with right left lobe larger.

Table III. - Synopsis of the caudal bursa in the Pudicinae. 
is also variable and several types of pattern with a predominance of characteristic types 2-2-1 and 1-4 (Table IV).

\section{DISCUSSION}

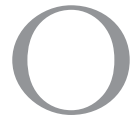
$f$ the five main patterns recognized among the Trichostrongylina treated by Durette-Desset (1985), only three were observed in the Heligmonellidae: 2-3, 2-2-1 and 1-3-1. In this article, the main feature considered was the grouping of the rays and, in the interpretation of its evolution, only two main tendencies were considered: the shortening of the dorsal ray and the lengthening of rays 4 .

\begin{tabular}{|c|c|c|c|}
\hline Genus & $\begin{array}{c}\text { Characteristic } \\
\text { symmetry }\end{array}$ & $\begin{array}{l}\text { Right } / \text { left } \\
\text { ratio }\end{array}$ & $\begin{array}{c}\text { Characteristic } \\
\text { pattern }\end{array}$ \\
\hline Bunomystrongylus & Variable & RL derived & - \\
\hline Carolinensis & Variable & Same pattern & $2-2-1$ \\
\hline Euzetoda & CB SS & Same pattern & $2-3$ t $2-2-1$ \\
\hline Guerrerostrongylus & CB SS & Same pattern & $1-3-1$ \\
\hline Hasanuddinia & CB SS & RL derived & $2-2-1$ \\
\hline Hassalstrongylus & Variable & Same pattern & $1-4,2-2-1,1-3-1$ \\
\hline Heligmonina & CB DS LL+ & LL derived & 1-3-1 RL, 1-4 LL \\
\hline Heligmonoides & CB DS LL+ & Variable & $2-2-1$ \\
\hline Hypocristata & CB SS & Variable & $1-3-1$ \\
\hline Malaistrongylus & CB SS & Same pattern & $2-2-1$ \\
\hline Malvinema & CB DS RL+ & Variable & $1-4$ \\
\hline Mammanidula & CB AS RL+ & Variable & $2-2-1$ \\
\hline Mawsonema & CB SS & Same pattern & $2-3$ \\
\hline Maxomystrongylus & BC DS LL+ & Variable & $2-2-1$ \\
\hline Melomystrongylus & variable & Unknown & $2-3$ \\
\hline Montistrongylus & CB DS RL+ & RL derived & $2-2-1$ \\
\hline Neoheligmonella & CB SS & Variable & $2-3$ t $2-2-1$ \\
\hline Nippostrongylus & $\begin{array}{l}\text { CB AS RL+ } \\
\text { CB DS RL+ }\end{array}$ & LL derived & $\begin{array}{l}1-3-1,4-1 \mathrm{RL} \\
4-1,3-1-1 \mathrm{LL}\end{array}$ \\
\hline Odilia & Variable & Variable & $2-2-1,1-4$ \\
\hline Orientostrongylus & CB SS & Same pattern & $2-2-1$ \\
\hline Paraheligmonelloides & Variable & Same pattern & $2-2-1,1-4$ \\
\hline Parasabanema & CB SS & Same pattern & $2-2-1$ \\
\hline Rattustrongylus & Variable & Same pattern & $2-2-1$ \\
\hline Sabanema & CB DS RL+ & Variable & $2-2-1$ \\
\hline Spalacina & CB SS & Same pattern & $1-4$ \\
\hline Stilestrongylus & CB DS RL+ & Variable & $2-2-1,1-4$ \\
\hline Suttonema & CB DS RL+ & Same pattern & $1-4$ \\
\hline Trichofreitasia & CB SS & Same pattern & $2-2-1$ \\
\hline Yatinema & Variable & RL derived & $2-2-1$ \\
\hline
\end{tabular}

CB SS: caudal bursa subsymmetrical. LL: left lobe of caudal bursa. RL: right lobe of caudal bursa. CB DS LL+: caudal bursa dissymmetrical with left lobe larger. CB DS RL+: caudal bursa dissymmetrical with right lobe larger. LL derived: left lobe of the caudal bursa having a pattern derived with respect to that of the right lobe. RL derived: right lobe of the caudal bursa having a pattern derived with respect to that of the left lobe.

Table IV. - Synopsis of the caudal bursa in the Nippostrongylinae.
In the present article, we provide an additional feature at the descriptive level, which is the sequence of the origin of the rays from the common trunk. Consequently, the presence of a new basic pattern (type 1-4) is highlighted, plus the presence of intermediary types: type $2-3$ tending to $2-2-1$, type $2-2-1$ tending to $1-3-1$, type 1-3-1 tending to $1-4$ and type $2-2-1$ tending to $1-$ 4 , which have enabled us to attempt an evolutionary interpretation of the patterns.

Type 2-3, the basal type, is somewhat infrequent, but not the following intermediary type, 2-3 t 2-2-1, which is common and present in all four subfamilies. The basic type, 2-2-1, seems to be the most consistent pattern in the family: it is the most frequent characteristic pattern, is present in all four subfamilies, and there are relatively few intermediary types from 2-2-1 to $1-3-1$, to $1-4$ or to atypical patterns. Types $1-3-1$ and 1-4 are less frequent than type 2-2-1 but are characteristic of several genera; type 1-3-1 is observed in all four subfamilies, and is the origin of several atypical types (4-1, 3-1-1, 1-2-2 and 1-2-1-1); type 1-4, characteristic of laterally elongated lobes, is absent from the Heligmonellinae. Finally, the family Heligmonellidae is characterized by the fact that, regardless of the pattern, with very few exceptions, rays 4 and 5 are always the last to diverge from the common trunk of rays 2 to 6 .

It is clear that a dissymmetrical or asymmetrical caudal bursa should be regarded as derived with respect to a subsymmetrical one. However, the type of symmetry has been actually considered a character of little value above the species level, since the asymmetrical bursae and mostly the dissymmetrical bursae have arisen several times during the course of evolution. The dissymmetry usually involves the transverse (lateral) lengthening of one of the lobes. This dissymmetry probably plays a role in holding the female during copulation (Durette-Desset, 1985). The most conspicuous asymmetries and dissymmetries are found among the Nippostrongylinae. In species with a slight dissymmetry the lengthening may or may not modify the bursal pattern, which usually remains the same in both lobes. In species with strong dissymmetry, species, which are usually tightly coiled spirally, the pattern is usually different for each lobe.

Independent of the type of symmetry, both lobes of the caudal bursa may have the same or different patterns. In the latter case the most frequent situation from an evolutionary point of view is one lobe having one pattern and the other lobe showing the "next" intermediary or basic type (e.g. Neobeligmonella 2-3 t 2-2-1 and 2-2-1; Heligmonina 1-3-1 and 1-4); there are very few cases in which both lobes have a totally different pattern (e.g. Heligmonella asymmetrica, some species of Stilestrongylus). 
In some genera the same "right/left ratio" is observed in all or most species in the genus: either both lobes have the same pattern (Heligmostrongylus, Pudica), or it is always the same lobe, which is derived with respect to the other (Heligmonina). Other genera are less homogeneous and the right/left ratio varies among the species of the genus (Neoheligmonella, Paraheligmonina).

The combination of the right/left ratio and type of symmetry gives disparate results: in genera with marked dissymmetry or asymmetry, the hypertrophied lobe is usually the same but it may show either the derived pattern (Heligmonina, LL) or the basal pattern (Nippostrongylus, RL). In genera with subsymmetrical or slightly dissymmetrical caudal bursae, not only may the right/left ratio vary but also the type of symmetry within each genus (Odilia, Paraheligmonina).

It is interesting to note that the Heligmonellinae, the Brevistriatinae and the Pudicinae, in which most of the caudal bursae are subsymmetrical with the same pattern in both lobes, are parasitic in hosts, which are relatively ancient (mainly sciuromorph and caviomorph rodents, a few in insectivores and lagomorphs). The Nippostrongylinae, in which the symmetry and the pattern in both lobes are more variable, are parasitic in a group, which appeared more recently, the muroid rodents (mainly cricetids and murids).

\section{ACKNOWLEDGEMENTS}

The authors wish to thank both reviewers of the ms, I for their critical remarks, which allowed a significant improvement of the text. They also thank Didier Kuriyama (Pôle Dessin, UMS 2700) of the Muséum national d'Histoire naturelle (MNHN, Paris, France) for the iconography. The second author thanks the MNHN for the invitation 2009-2010 to the Département de Systématique et Evolution headed by G. Lecointre; and the Consejo Nacional de Investigaciones Científicas y Técnicas (CONICET) from Argentina for technical support through grant PIP 0006.

\section{REFERENCES}

Beveridge I. \& Durette-Desset M.C. The morphology of Nippostrongylus magnus, a parasite of native Australian rodents. Transactions of the Royal Society of South Australia, 1992, 116, 109-115.

Biserkov V.Y., Durette-Desset M.C. \& Genov T. Spalacina yanchevi n. gen. n. sp. (Nematoda: Heligmonellidae) from the lesser mole Spalax leucodon Nordmann (Rodentia, Spalacina). Systematic Parasitology, 1995, 32, 27-32.

Blaxter M.L., De Ley P., Garey J., Liu L.X., Scheldeman P.,
Vierstraete A., Vanfleteren J., Mackey L.Y., Dorris M., Frisse L.M., Vida J.T. \& ThOmas W.K. A molecular evolutionary framework for the phylum Nematoda. Nature, 1998, 392, 71-75.

Blaxter M.L. Molecular analysis of nematode evolution, in: Parasitic nematodes: molecular biology, biochemistry and immunology. Hartnett M.W. (ed), CABI, Wallingford, 2001, 1-24.

Cassone J. \& Durette-Desset M.C. Cinq espèces (dont trois nouvelles) de Nématodes Trichotrongyloïdes coparasites de Dasyprocta azarae au Paraguay. Revue Suisse de Zoologie, 1991, 98, 229-242.

Chabaud A.G., Puylaert F., Bain O., Petter A.J. \& DuretteDesset M.C. Remarques sur l'homologie entre les papilles cloacales des Rhabditides et les côtes dorsales des Strongylida. Comptes Rendus de l'Académie des Sciences, Série D, 1970, 271, 1771-1774.

Digiani M.C., Carreño R.A. \& Durette-Desset M.C. A new heligmonellid (Nematoda) from Sylvilagus floridanus (Leporidae) in Costa Rica, with some comments on species of Parabeligmonella Durette-Desset, 1971. Journal of Parasitology, 2009, 95, 673-677.

Digiani M.C., SutTon C.A. \& Durette-Desset M.C. A new genus of Nippostrongylinae (Nematoda: Heligmonellidae) from the water rat Scapteromys aquaticus (Sigmodontinae) in Argentina. Journal of Parasitology, 2003, 89, 124-132.

Digiani M.C. \& Durette-Desset M.C. Trichostrongylina (Nematoda) parasitic in Phyllotis sp. (Rodentia: Sigmodontinae) from Argentina, with description of three new species. Parasitology International, 2007, 56, 9-18.

Diouf M., Daouda I. \& Durette-Desset M.C. Two new species of Nippostrongylinae (Nematoda, Trichostrongylina, Heligmonellidae) coparasites of Mastomys natalensis (Muridae, Murinae) from Benin. Zoosystema, 2005, 27, 27-35.

DuretTE-Desset M.C. Sur deux nouveaux Trichostrongyles parasites du Porc-Épic au Viet-Nam. Annales de Parasitologie Humaine et Comparée, 1966, 41, 453-466.

Durette-Desset M.C. Nématodes Héligmosomes d'Amérique du Sud. I. Description de deux nouvelles espèces: Stilestrongylus freitasi, parasite de Zygodontomys lasiurus et Viannella lenti, parasite de Galea spixi. Bulletin $d u$ Muséum National d'Histoire Naturelle, $2^{\text {ème }}$ série, 1968a, 40, 403-412.

Durette-Desset M.C. Nématodes Héligmosomes d'Amérique du Sud. II. Nouvelles données morphologiques sur quatre espèces du genre Heligmodendrium. Bulletin du

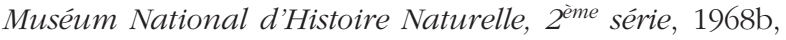
40, 612-620.

Durette-Desset M.C. Étude du système des arêtes cuticulaires de trois Nématodes Héligmosomes: Longistriata kinsellai n. sp., L. seurati Travassos et Darriba, 1929, L. bokkaidensis Chabaud, Rausch et Desset, 1963, parasites de Rongeurs. Annales de Parasitologie Humaine et Comparée, 1969, 44, 617-624.

Durette-Desset M.C. Nématodes Héligmosomes d'Amérique du Sud. VI. Étude de cinq espèces, parasites de Rongeurs Dasyproctidés. Bulletin du Muséum National d'Histoire Naturelle, 2ème série, 1970a, 42, 590-600. 
DuretTe-Desset M.C. Nématodes Héligmosomes d'Amérique du Sud. VIII. Description de six nouvelles espèces parasites de Cricétidés. Bulletin du Muséum National d'Histoire Naturelle, 2ème série, 1970b (publ. 1971), 42, 730-744.

Durette-Desset M.C. Description de deux nouveaux Nématodes Héligmosomes chez un Sciuridé du Népal. Bulletin

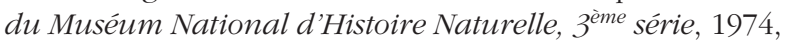
232 Zoologie, 156, 819-825.

Durette-Desset M.C. Trichostrongyloid nematodes and their vertebrate hosts: reconstruction of the phylogeny of a parasitic group. Advances in Parasitology, 1985, 24, 239306.

Durette-Desset M.C., Beveridge I. \& Spratt D. The origin and evolutionary expansion of the Strongylida (Nematoda). International Journal for Parasitology, 1994, 1, 1139-1165.

Durette-Desset M.C. \& Chabaud A.G. Nouvel essai de classification des Nématodes Trichostrongyloidea. Annales de Parasitologie Humaine et Comparée, 1981, 56, 297-312.

Durette-Desset M.C. \& Chabaud A.G. Nomenclature des Strongylida au-dessus du groupe famille. Annales de Parasitologie Humaine et Comparée, 1993, 68, 111-112.

Durette-Desset M.C. \& Digiani M.C. Taxonomic revision of the type specimens of Ethiopian Nippostrongylinae (Nematoda) deposited at the Natural History Museum of London. Zootaxa, 2010, 2494, 1-28.

Durette-Desset M.C., Digiani M.C., Mahlaba T. \& Behnké J.M. Description of a new species of Heligmonina Baylis, 1928 (Nematoda, Trichostrongylina) a parasite of Mastomys natalensis (Muridae) from Swaziland and new data on the synlophe of Heligmonina chabaudi Desset, 1966. Parasite, 2007, 14, 271-280.

DuretTe-Desset M.C. \& GiBson D.I. Neoheligmonella acomysi n. sp. (Trichostrongyloidea, Nippostrongylinae), parasite d'Acomys dimidiatus (Muridae) de Somalie. Systematic Parasitology, 1990, 17, 109-113.

Durette-Desset M.C. \& Guerrero R.A. A new species of Hypocristata (Nematoda, Trichostrongylina, Heligmosomoidea), a parasite of Sigmodon bispidus (Cricetidae, Sigmodontinae) from Venezuela. Parasite, 2006, 13, 201-204.

Durette-Desset M.C. \& VAucher C. Nématodes Héligmosomes parasites d'insectivores Talpidés de la région holarctique. Annales de Parasitologie Humaine et Comparée, 1974, 49, 191-200.

HasegaWA H. \& SyafrudDin. Nippostrongylus marbaeniae sp. n. and other nematodes collected from Rattus cf. morotaiensis in North Halmahera, Molucca Islands, Indonesia. Journal of the Helminthological Society of Washington, 1995, 12, 111-116.

Osche G. Die Bursa- und Schwanzstrukturen und ihre Aberrationen bei den Strongylina (Nematoda); morphologische Studien zur Problem der Pluri- und Paripotenzerscheinungen. Zeitschrift für Morphologie und Oekologie der Tiere, 1958, 46, 571-635.

Smales L.R. \& HeInRICH B.B. Gastrointestinal nematodes of Paramelomys rubex (Rodentia: Muridae) from Papua Indonesia and Papua New Guinea with the descriptions of three new genera and four new species of Heligmonellidae and Herpetostrongylidae (Nematoda: Trichostrongylida). Zootaxa, 2010, 2672, 1-28.

Travassos L. Contribution à l'étude de la faune helminthologique du Brésil. XIII. Essai monographique sur la famille des Trichostrongylidae Leiper, 1909. Memórias do Instituto Oswaldo Cruz, 1921, 13, 1-82.

Travassos L. Tricostrongilideos de mamiferos. Revista Brasileira de Biologia, 1943, 3, 345-349.

Received on October $10^{\text {th }}, 2011$ Accepted on November $18^{\text {th }}, 2011$ 